\title{
CSTRPubishing Australian Journal of Soil Research
}

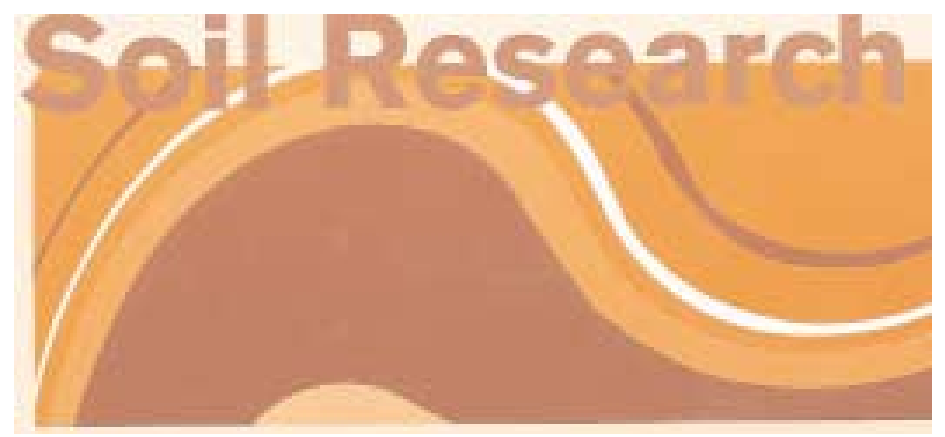

VOLUME 40, 2002

(C) CSIRO 2002

An international journal for the publication of original research into all aspects of soil science

All enquiries and manuscripts should be directed to:

Australian Journal of Soil Research

CSIRO Publishing

PO Box 1139 (150 Oxford St)

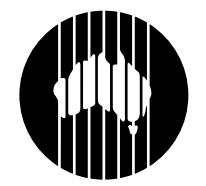

Collingwood, Vic. 3066, Australia

Telephone: +61 396627628

Fax: +61 396627611

C S I RO

Email: publishing.sr@csiro.au

Published by CSIRO Publishing

for CSIRO and the Australian Academy of Science

www.publish.csiro.au/journals/ajsr 


\title{
The rapid assessment of concentrations and solid phase associations of macro- and micronutrients in alkaline soils by mid-infrared diffuse reflectance spectroscopy
}

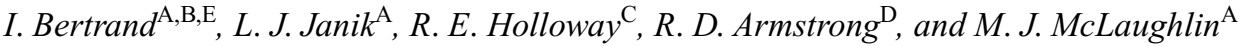 \\ ${ }^{A}$ CSIRO Land \& Water, Adelaide Laboratory, PMB 2, Glen Osmond, SA 5064, Australia. \\ ${ }^{B}$ INRA - Unité d'Agronomie de Reims, 2 Esplanade Roland Garros, BP 224, \\ 51686 Reims Cedex 2, France. \\ ${ }^{\mathrm{C}}$ SARDI, Minnipa Research Centre, Minnipa, SA 5654, Australia. \\ ${ }^{\mathrm{D}}$ Agriculture Victoria, Victorian Institute for Dryland Agriculture, Natimuk Rd, Private Bag 260, \\ Horsham, Vic 3400, Australia. \\ ${ }^{\mathrm{E}}$ Corresponding author; email: Isabelle.bertrand@reims.inra.fr
}

Abstract

Chemical analysis is a crucial but often expensive and time consuming step in the characterisation of soils. Mid-infrared diffuse reflectance (MIR-DRIFT) spectroscopy coupled with partial least square (PLS) analysis was used to determine macro- and micronutrient concentrations of a range of alkaline soils from southern Australia. Solid phase associations of macro- and micronutrients were also investigated using the mineralogical information contained in the infrared spectra of soil samples. Results showed that MIR-PLS analysis is a powerful and rapid technique for the accurate prediction of more than 15 chemical properties from each soil sample spectrum. Correlation coefficients for MIR derived concentration versus laboratory determined values were greater than $R^{2}=0.80$ for soil moisture, calcium carbonate concentration, total concentration of $\mathrm{Mg}, \mathrm{K}, \mathrm{S}, \mathrm{Fe}, \mathrm{Al}, \mathrm{Mn}, \mathrm{Zn}, \mathrm{Cu}$, and oxalate-extractable $\mathrm{Al}, \mathrm{Fe}, \mathrm{Mn}$, and $\mathrm{Si}$. In calcareous soils, sulfur was associated with carbonate and conversely $\mathrm{Mg}$ was more related to the clay concentration of soils. Micronutrients such as $\mathrm{Fe}, \mathrm{Zn}, \mathrm{Mn}$, and $\mathrm{Cu}$ were positively associated with smectite/illite in the clay fraction and negatively with kaolinite. The potential use of these results in partitioning model to assess plant available micronutrients pools is discussed.

Additional keywords: alkaline soils, mid-infrared spectroscopy, carbonates, clays.

\section{Introduction}

Alkaline soils represent an important proportion of world soils but are often associated with fertility problems such as sodicity and nutrient deficiencies (Matar et al. 1992; Ford et al. 1993). Calcarosols, Vertosols, and alkaline Duplex soils, as defined by McKenzie et al. (1999), are amongst the most common Australian alkaline soils. These soils represent the majority of soils used for grain production in southern Australia. For example, highly calcareous soils cover an area $>1$ million hectares and they produce $40 \%$ of South Australia's wheat crop (Holloway et al. 2001). In Victoria, alkaline sodic soils, i.e. Duplex soils or cracking clays, represent $50 \%$ of the total agricultural area (Ford et al. 1993; Peverill et al. 1999). The major constraints for agricultural productivity associated with alkaline soils include micronutrient deficiencies ( $\mathrm{Zn}, \mathrm{Cu}, \mathrm{Mn}, \mathrm{Fe}$ ) and/or toxicities (e.g. B), a constant need for inputs of $\mathrm{N}$ and $\mathrm{P}$, and poor soil physical structure resulting from sodicity.

The agronomic potential of soils can be partly assessed using chemical analyses. However, current methods for the determination of chemical characteristics and nutrient concentrations in soils are both time consuming and costly. Also, chemical extractions, generally performed to assess soil fertility, are often poor predictors of the bioavailability 
of many elements (Simpson et al. 1997; Saggar et al. 1999). Consequently there is an increasing need to develop a rapid method to accurately assess soil chemical characteristics. However, total concentrations may not adequately describe the relationships between macro- or micronutrients and major soil chemistry. It may be more appropriate to model the nutrient and micronutrient concentrations according to their relationships with soil mineralogy, e.g. clay, iron oxides, and with the type of organic matter in order to predict element availability. Soil fractionation procedures and sequential extractions have been developed to address these problems (for example Chang and Jackson 1957, for phosphorus). However, the numerous procedures available in the literature all suffer from a lack of specificity for the extracting solution used (Barbanti et al. 1994; Flores-Vélez et al. 1996). Consequently, the distribution and binding of chemical elements among different soil mineral phases remains difficult to determine.

Mid-infrared (MIR) spectroscopy offers a potential alternative and a much faster and cheaper method for determining soil macro- and micronutrient concentrations. MIR has been widely used in soil chemistry to separate and identify soil organic compounds (Schnitzer 1965). More recently, partial least square (PLS) regression has been used for the quantitative prediction of organic carbon and nitrogen concentrations in peats (Holmgen and Norden 1988). However, only a few studies have reported the use of MIR-PLS analysis for soil chemical characterisation. Janik et al. (1995, 1998) and Janik and Skjemstad (1995) have used MIR diffuse reflectance (DRIFT) spectroscopy coupled with PLS analyses to predict major elemental composition of a large range of Australian soils determined by X-ray fluorescence (XRF), and other common laboratory measurements such as $\mathrm{pH}$, organic carbon, carbonate, and clay concentrations. However, no published report exists on the success of MIR-DRIFT to predict micronutrient concentrations in alkaline soils and on the use of the supplementary mineralogical and organic information offered by MIR to determine the soil constituents with which micronutrients are associated.

The aims of this study were (i) to assess the validity of using MIR-DRIFT spectroscopy, coupled with PLS, to determine chemical characteristics, and nutrient and micronutrient concentrations of highly contrasting alkaline soils from southern Australia, and (ii) to use MIR-PLS analysis to determine the major mineral phases responsible for retention of nutrients and/or pollutants in alkaline soils.

\section{Materials and methods}

\section{Soil samples}

Surface soil samples (10 cm depth) from 48 alkaline soils were collected from southern Australia. Soil pH measured in 1:5 soil: water extracts according to Rayment and Higginson (1992) had a mean of 8.48 \pm 0.41 . Most of the soils collected had been cropped for at least 25 years and had received regular applications of macronutrients (especially $\mathrm{P}$ and $\mathrm{N}$ ) and micronutrients (mainly $\mathrm{Zn}$ ) at variable rates. Sampling was performed mainly in 2 regions, i.e. northern agricultural South Australia (upper Eyre Peninsula) and western Victoria. These regions have a Mediterranean climate with mean annual rainfall ranging from $300 \mathrm{~mm} /$ year for upper Eyre Peninsula to $500 \mathrm{~mm} /$ year for western Victoria.

Of the 25 soils collected from western Victoria, 6 were from the Wimmera area and classified as Grey and Brown Vertosols (Isbell 1996), 9 were from the southern Mallee and were classified as alkaline Duplex soils, 6 were from the central Mallee and were identified as Sodosols, and 4 were from the northern Mallee and were classified as Vertosols for two of them and as Red Brown Calcareous soils for the two other. According to the classification of Isbell (1996), the 23 soil samples collected from Upper Eyre Peninsula were classified as Supravescent and Hypervescent Calcarosols. The soil samples were air-dried and sieved to $<2-\mathrm{mm}$ before storing at room temperature prior to analysis. 
Chemical soil analyses

Concentrations of nutrients and micronutrients in soils were determined after extraction and microwave heating following the USEPA SW 3051A method (USEPA 1993). Ca, S, Na, B, Al, Fe, K, Mg, P, Mn, Cu, and $\mathrm{Zn}$ were determined by inductively coupled plasma-atomic emission spectroscopy (ICP-AES). Oxalate-extractable $\mathrm{Al}\left(\mathrm{Al}_{\mathrm{ox}}\right), \mathrm{Fe}\left(\mathrm{Fe}_{\mathrm{ox}}\right), \mathrm{Mn}\left(\mathrm{Mn}_{\mathrm{ox}}\right)$, and $\mathrm{Si}\left(\mathrm{Si}_{\mathrm{ox}}\right)$ were determined according to the method of McKeague and Day (1966). Organic carbon and organic $\mathrm{P}$ were measured following the procedures of Heanes (1984) and Walker and Adams (1958), respectively. Analyses of $\mathrm{CaCO}_{3}$ were performed according to the procedure of Martin and Reeve (1955). Air-dry moisture and moisture content at $120 \mathrm{~cm}$ water-tension (water holding capacity, WHC) were determined following methods $2 \mathrm{~A} 1$ and $2 \mathrm{C} 1$ respectively by Rayment and Higginson (1992).

\section{Clay fraction extraction and characterisation}

The clay fractions $(<2 \mu \mathrm{m})$ were extracted using a procedure according to Jackson (1956) and the clay concentration of the soils was then deduced from the total amount of clay collected from each soil sample. Iron and aluminium oxy-hydroxides were extracted from the clay fractions when sufficient clay was present (i.e. 32 samples) by using a citrate bicarbonate dithionite (CBD) solution according to McKeague and Day (1966). Fe and Al concentration in the extracts were measured by ICP-AES analysis. Concentrations of nutrients and micronutrients were also determined on the clay fractions using the procedures described above for the whole soil sample.

X-ray diffraction (XRD) analyses were performed on some clay fractions using a Philips PW1800 microprocessor-controlled diffractometer with Co K $\alpha$ radiation, and graphite monochromator. Quantitative analysis of the XRD data was performed using the commercial software package SIROQUANT from Sietronics Pty Ltd.

\section{Infrared analysis}

All spectra were recorded on a rapid scanning Fourier Transform Spectrometer (BioRad FTS-175C) scanning at $1 \mathrm{scan} / \mathrm{sec}$, with an extended range $\mathrm{KBr}$ beamsplitter and Peltier-cooled DTGS detector, and with a full spectral range of $8300-470 \mathrm{~cm}^{-1}$ at $8 \mathrm{~cm}^{-1}$ resolution. Sampling was by diffuse reflectance from the powdered sample surface using an off-axis diffuse reflectance accessory (Harrick DRS-3SO). Spectral frequencies were referenced against an internal $\mathrm{He}-\mathrm{Ne}$ laser to give a precision of $0.01 \mathrm{~cm}^{-1}$. A KBr blank was used to test spectrometer performance and as a reference for the sample spectra. Acquisition and processing of each spectrum took about $1 \mathrm{~min}$ per sample over 60 co-added scans. The sample absorbance spectra were directly acquired in IBM-PC Grams-32 format (Galactic NH).

Subsamples of soils used for chemical analysis were ground in an orbital mill with a stainless steel ball (Siebtechniqe) to obtain a minimum particle size of $100 \mu \mathrm{m}$ for MIR analysis. A comparison of 2 methods was then used for MIR: (i) after 1 min of grounding, soil samples were directly scanned by MIR as neat powders using the diffuse reflectance infrared method outlined by Janik et al. (1995), or (ii) $0.1 \mathrm{~g}$ of soil samples was diluted with $1 \mathrm{~g}$ powdered $\mathrm{KBr}(10 \% \mathrm{w} / \mathrm{w})$ and ground for $1 \mathrm{~min}$. All samples were then immediately transferred to a sample holder and the surfaces of the powders were levelled. Spectra of all clay fractions were determined only on neat samples.

The specific software used for both principal component analysis (PCA) and partial least squares (PLS) was PLSplus/IQ V4.05 (Galactic) within Grams-32 (Galactic NH). The spectra were averaged over successive 3 points segments, in order to reduce computation time. The optimum frequency range (4000$1030 \mathrm{~cm}^{-1}$ ) and number of PLS terms (factors) were determined empirically to give maximum cross-validation $R^{2}$ values which corresponded to the minimum standard error of cross-validation (SECV). In this paper, all references to regression coefficients $\left(R^{2}\right)$ were determined following cross-validation. Spectra were baseline corrected and mean centered.

\section{Partial least squares and principal component analysis}

The procedure for PLS analysis was adapted from the PLS1 method of Haaland and Thomas (1988). Essentially, an X data variable array and corresponding properties are transformed into a smaller set of mutually orthogonal factors, which are used as subsequent predictor variables. These factors are characterised by loading vectors which include a loading for each reflectance value (eigenspectra), loading weights which represent the importance in the spectra with respect to concentration, and scaling terms for the loading called scores. The original spectrum for each sample in the $\mathrm{X}$ array can be reconstructed from a linear combination of loadings and scores. Most of the spectral and property information is represented 
by the first 2 loadings. The scores can be used to provide scatter plots maps of the sample variability or combined with the PLS regression coefficients to yield predictions, whilst loading weights give qualitative information on the correlation between the spectra and sample properties or concentrations. Although the first loading weight is in essence a spectrum of the 'pure' soil components correlating most strongly with the soil properties, subsequent loading weights show variation within this 'pure' component spectrum, i.e. minor components or frequency shifts and aberrations.

A PCA using the Grams PLSplus-IQ self-prediction option for a maximum of 23 factors was performed for the 48 neat soil samples (no outliers removed). The $4000-1030 \mathrm{~cm}^{-1}$ portion of the spectra was used and only 2 principal components were needed to account for $90.4 \%$ of the variance.

Calibration for the determination of soil properties by PLS were carried out by means of the 'leave-one-out' cross-validation procedure, a method based on the algorithm developed by Haaland and Thomas (1988).

Six different types of calibration were performed. The first type was a calibration between the laboratory-determined analyses and the analyses derived from MIR spectra of the whole soils (Table 1). The same types of calibrations were then performed for samples with and without carbonate (Table 2). The third type of calibration was performed between the laboratory-determined analyses of the clay fraction and the MIR-derived analyses from the spectrum of the clay fraction (Table 3). A calibration was then set up with measured laboratory analyses of the whole soil and the analyses derived from MIR of the clay fraction (Table 3). The 2 last calibrations were performed between the measured laboratory analyses of the whole soil and the MIR derived analyses from the spectrum of the clay fraction without carbonate and after a CBD extraction, respectively (Table 3 ).

\section{Results and discussion}

Assessing a grouping of the soil samples with common mineralogy

PCA was carried out using the PLSplus/IQ software so that sample variability according to their spectra could be assessed. The results of the PCA are depicted in Fig. 1, which shows a plot of scores for the principle component PC1 versus PC2 for the full set of neat soil spectra. PC1 was characterised by strong peaks at 2600-2520 and $1800 \mathrm{~cm}^{-1}$ due to carbonates (data not shown) and PC2 by positives peaks at $2000-1860 \mathrm{~cm}^{-1}$, which can be associated with quartz (Nguyen et al. 1991). Peaks due to clay minerals were also observed at $3620,3450,3300$, and $1200 \mathrm{~cm}^{-1}$ (data not shown) (Fig. 1). In spite of the relative small number of samples used in the training set, the PCA analyses demonstrated that only 2 factors would adequately describe over $90 \%$ of the variance. For the present study, fewer than 11 factors were usually sufficient to describe the model (Table 1).

The laboratory data from the 48 soil samples used in this study showed a wide distribution of physical and chemical properties (Fig. 1 and Table 1). Samples from the central Mallee exhibited the highest amount of sand, whereas those from the Eyre Peninsula were the most calcareous, and Wimmera and southern Mallee soils had high clay concentrations (Fig. 1). These results agree well with the proportions of the major phases (clay and carbonate concentrations) of the soils (Table 1). PCA coupled with near-infrared (NIR) spectrum has been used by Stenberg et al. (1995) to improve field-sampling protocols. They concluded that this method could reduce by up to $70 \%$ of the cost associated with specific soil analyses and was a useful tool for the selection of field sites. However, these authors made their evaluation with the emphasis on 5 specific soil properties important for soil fertility, i.e. clay concentration, soil organic matter, $\mathrm{CEC}, \mathrm{pH}$, and base saturation. Their results revealed that none of the methods tested were ideal for all 5 parameters. They finally proposed a peripheral selection from a 2-dimensional PCA plot and $\mathrm{pH}$ data. In the present study, the use of PCA loadings allowed the determination of the major mineral or organic constituents of the soil, together with a grouping of the soils as a function of their major mineralogical characteristics. The method improves the accuracy of 


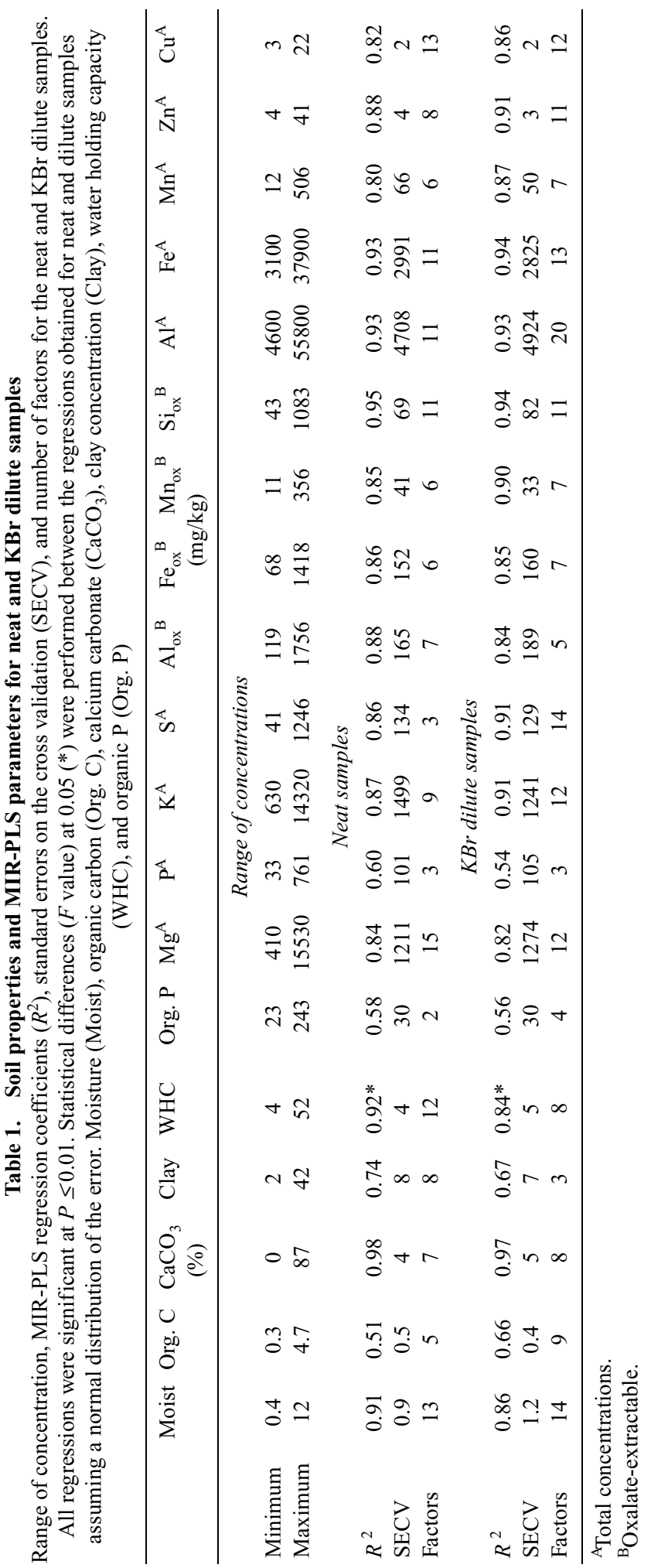




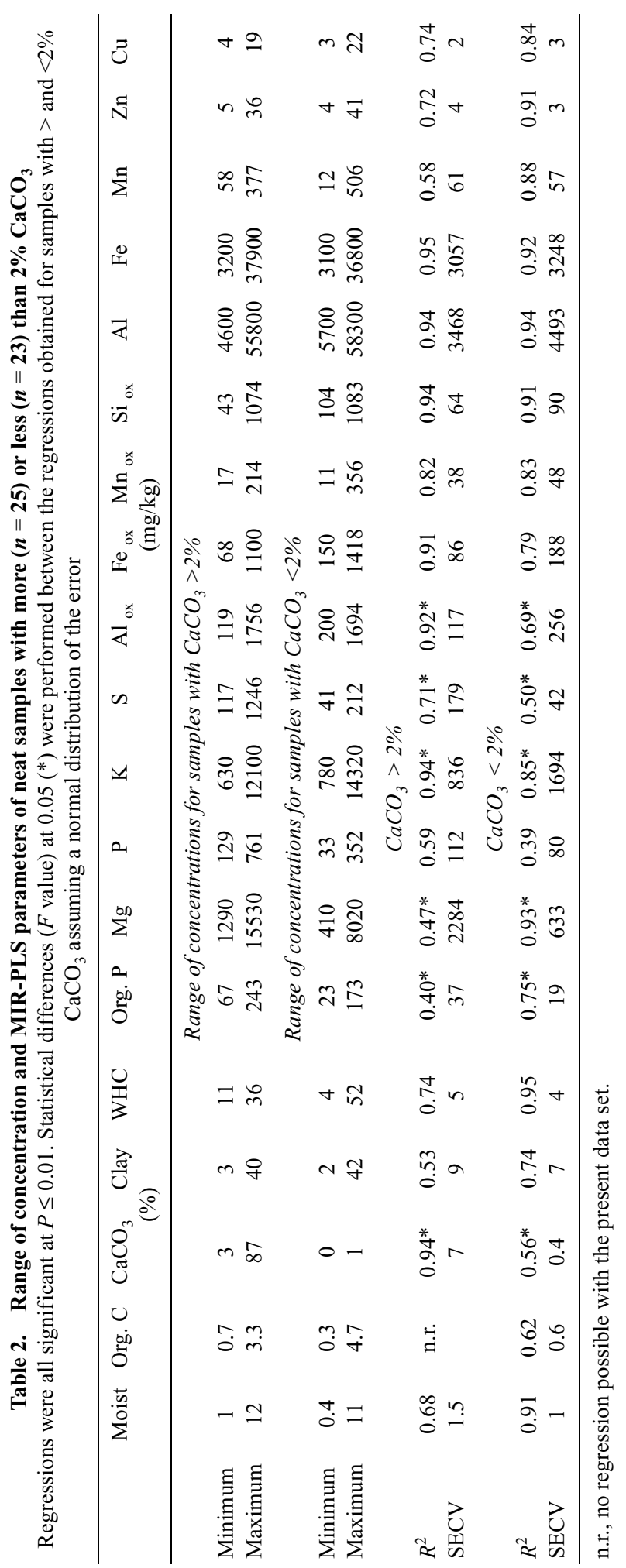




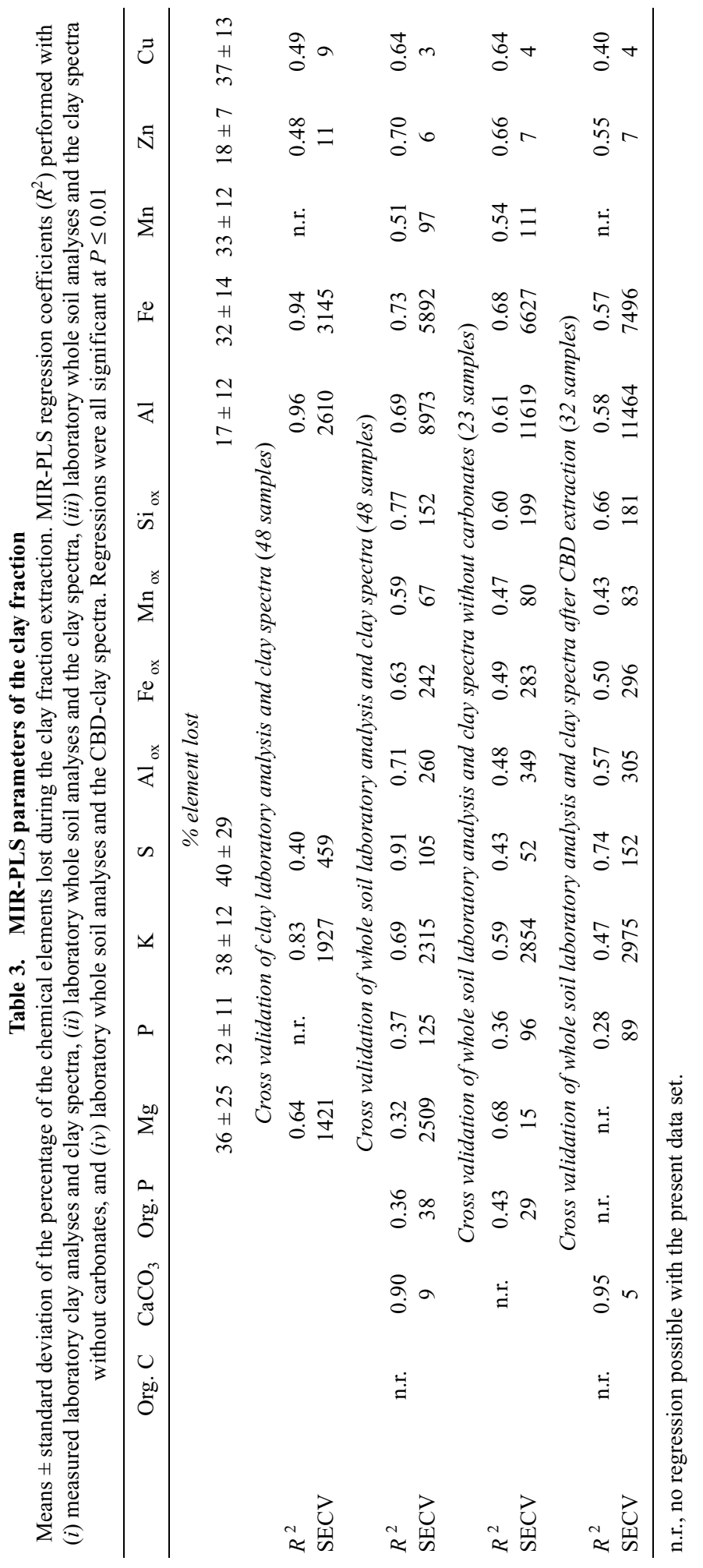




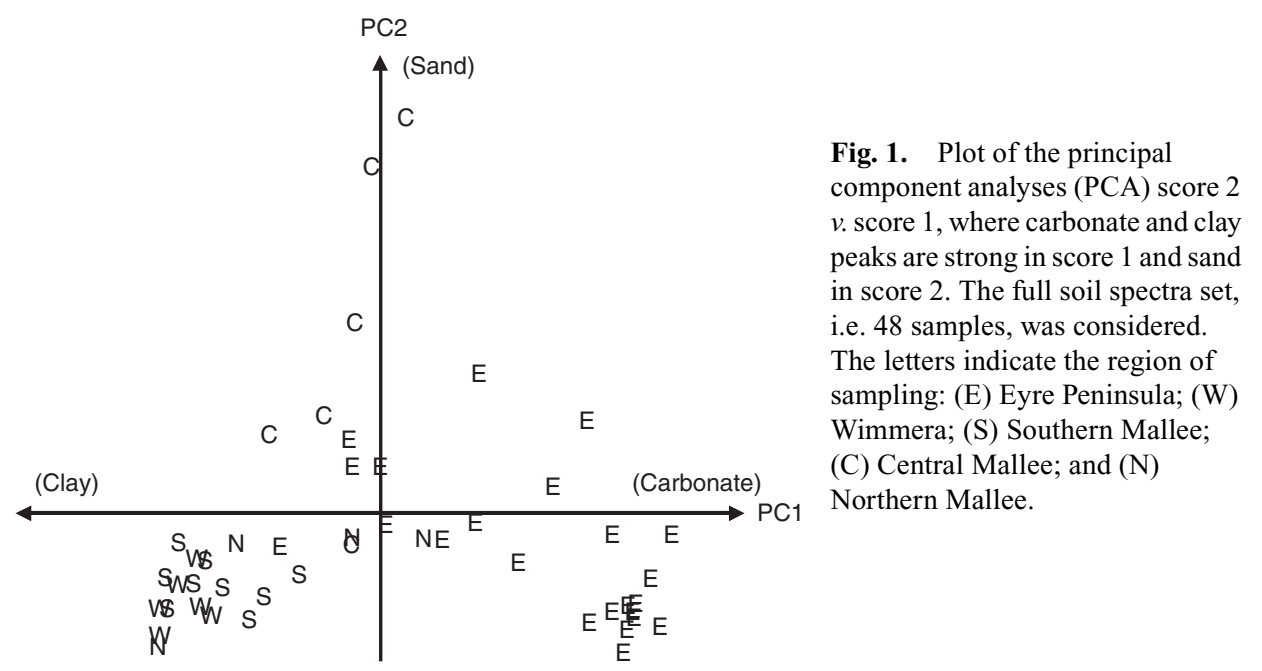

the sampling technique, by an objective selection of the soil samples directly from the mineralogical information contained in the IR spectrum.

\section{Effect of sample preparation techniques on PLS quantification}

Regression coefficients for PLS cross-validation $\left(R^{2}\right)$ are presented in Table 1 for the neat and $\mathrm{KBr}$ dilute samples. All samples were considered for PLS analysis and no outliers were identified or omitted. Of the 19 laboratory-determined soil characteristics presented in Table 1 , only 4 relationships had $R^{2}$ values $<0.80$ for the neat and dilute samples. Differences in regression coefficients between dilute and neat samples were generally low as indicated by the $F$-test values (Table 1 ), with only 1 analysis exhibiting a statistical difference at $P \leq 0.05$. Janik et al. $(1995,1998)$ and Nguyen et al. (1991) have stressed the advantages of analysing neat samples by MIR as it reduces sample preparation time, and eliminates weighing errors. However, to our knowledge no comparison of neat or $\mathrm{KBr}$ incorporated (dilute) soil samples has ever been published for the determination of soil properties by MIR-PLS. Our results prove that MIR of neat samples correlates well with a wide range of chemical analyses except for the determination of water holding capacity in soils (Table 1). However, even if the MIR-PLS regression coefficient, using the dilute method, was better in this case than for neat samples, there are several problems using the dilute method. The dilute method may have interferences that influence the regression coefficients, such as matrix effects that cause ion exchange (Piccolo and Stevenson 1982) or adsorption of water onto the particles used for the dilution, i.e. KBr. Consequently, taking into account the reduced sample preparation time and the elimination of possible artefacts resulting from the addition of $\mathrm{KBr}$ to the sample, there are significant advantages in utilising the neat sample method.

\section{PLS quantification of macro- and micronutrient concentrations}

Regression coefficients $\left(R^{2}\right)$ for nutrients such as $\mathrm{Mg}, \mathrm{K}$, and $\mathrm{S}$ were $>0.80$ (Table 1). In contrast, the $R^{2}$ for $\mathrm{P}$, one of the more important nutrients, was only 0.60 . Likewise, regression coefficients for organic carbon and organic phosphorus were $<0.60$. However, Janik et al. $(1995,1998)$ found a good correlation $\left(R^{2}=0.92-0.93\right)$ for the determination of organic carbon in soils by MIR-PLS analyses. The reasons for the poor regression 
coefficients for organic $\mathrm{C}$ and $\mathrm{P}$ in these alkaline soils are unclear. It is known that carbonates adsorbed strongly near 2900 and $1450 \mathrm{~cm}^{-1}$, a similar region to that of organic C. It is not unreasonable, therefore, that there might be significant interferences in these spectral regions leading to a decrease in the predictions accuracy for organic $\mathrm{C}$. In the case of organic and mineral $\mathrm{P}$, the range of concentrations studied was wide. Consequently, due to the variable nature of $\mathrm{P}$ associations in soils, such as Ca-P, Fe-P, Al-P compounds, there are few uniform phases which can be identified by MIR within this soil set.

Regressions obtained in this study are limited to alkaline soils. As shown in Table 1, the values of standard errors of cross validation (SECV) are generally larger than the minimum concentrations, so predictions for unknown samples at low concentrations should be interpreted with caution.

Micronutrient concentrations correlated highly with spectral features determined by MIR-PLS (Table 1). Janik et al. (1998) reported that DTPA-extractable Fe, Mn, Zn, and Cu were difficult to predict by MIR-PLS with regression coefficients $\left(R^{2}\right)$ of $0.55,0.57,0.24$, and 0.20 , respectively. They concluded that MIR was unlikely to provide quantitative data when $(i)$ the soil property being predicted was not related to the major constituent of the soil, or (ii) the soil solution concentrations were too low, or not in equilibrium, with the solid phases. DTPA extractions were probably less related to the soil constituents than those using stronger extractants such as oxalate. In addition, oxalate extractions are well known as extractants for the amorphous fraction of iron and aluminium oxides in soil and consequently are directly related to soil mineralogy (Schwertmann 1964).

The correlations of spectral features with micronutrient concentrations were surprisingly good, considering the low elemental concentrations (Table 1). For example, $\mathrm{Cu}$ and $\mathrm{Zn}$ concentrations ranged from 3 to 22 and 4 to $41 \mathrm{mg} / \mathrm{kg}$, respectively. Such small changes in concentration over a wide range of alkaline soils cannot be measured directly by MIR, and the correlations are probably related to other soil properties involving the major soil components. Malley et al. (1999) have shown that NIR was able to predict Mn concentration in 28 Canadian soil samples from 3 boreholes down to a depth of $10 \mathrm{~m}$. However, all their soils were from one soil type and one location and it was concluded that their results could not be used for prediction in other soil types or location.

Compounds consisting of metal cationic species such as $\mathrm{Mn}, \mathrm{Cu}, \mathrm{Zn}$, and to a lesser extent $\mathrm{Al}$ and Fe can absorb strongly in the mid- and near-infrared wavelength bands. Their direct detection at such low concentrations $(<100 \mathrm{mg} / \mathrm{kg})$, however, is probably not possible. The good regressions obtained may be due to the association of these metals with strongly O-H absorbing groups, such as those present at the surface of clays or organic matter (Krischenko et al. 1992), or to their association with $\mathrm{CO}_{3}{ }^{2-}$ groups (Ben-Dor and Banin 1990). Nevertheless, Fig. 2 shows a linear plot of the data along the regression line for $\mathrm{Fe}, \mathrm{Cu}, \mathrm{Zn}$, and $\mathrm{Mn}$, and a similar relationship was obtained for $\mathrm{Al}, \mathrm{Fe}_{\mathrm{ox}}, \mathrm{Al}_{\mathrm{ox}}$, and $\mathrm{Mn}_{\mathrm{ox}}$. The SECV values (Table 1) were generally lower than the minimum measured concentrations for $\mathrm{Mn}, \mathrm{Zn}$, and $\mathrm{Cu}$, which indicates the high quality of the regressions over the range of concentrations studied.

Figure $3 a$ depicts the first loading weight for Fe. This loading weight is characterised by the spectral signatures of soil components correlating with Fe concentration, e.g. Fe-oxy-hydroxides and Fe substitution within carbonates and clays. This loading weight was also characteristic for the other trace elements $(\mathrm{Cu}, \mathrm{Zn}, \mathrm{Mn})$, which are apparently associated with similar soil mineralogy. As already shown by Janik et al. (1995), generally the first few PLS loading weights are sufficient to describe the main relationships between soil mineral phases and measured chemical properties. The first weight spectrum for Fe, 


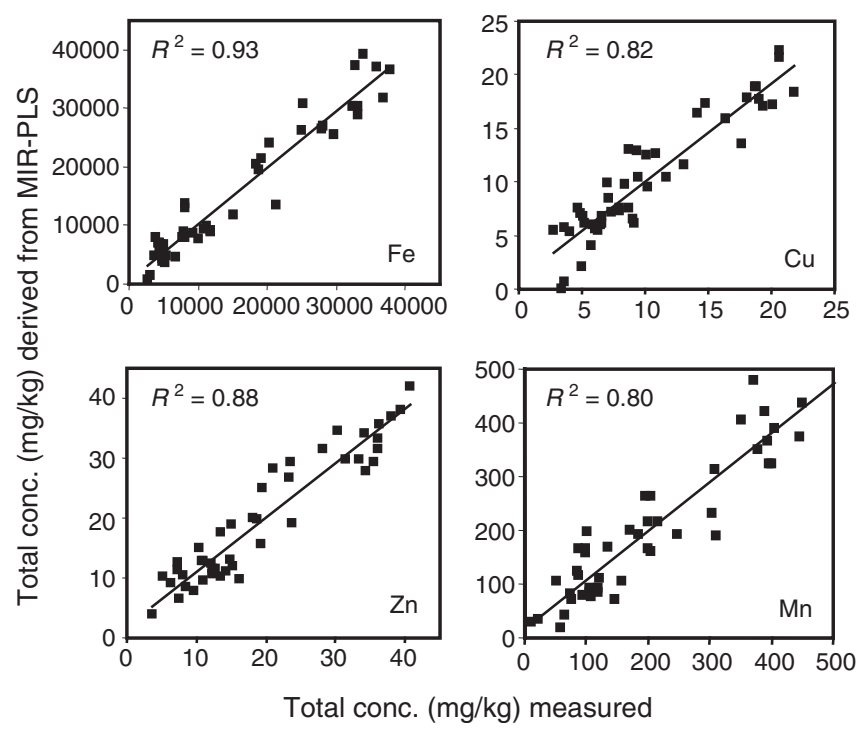

Fig. 2. Calibration relationships between concentrations derived from MIR-PLS analyses $v$. concentrations measured by microwave extraction for iron $(\mathrm{Fe})$, copper $(\mathrm{Cu})$, zinc $(\mathrm{Zn})$, and manganese (Mn). Analyses were performed from the full soil spectra set $(n=48)$ obtained from the neat sample.

typical of those for the other metal concentrations in soils (Fig. $3 a$ ), showed strong positive peaks, which after comparison with standard materials (Fig. 4) were attributed to 2:1 layer alumino-silicate clay minerals such as smectites, illites, and interstratified illite/smectites and kaolin/smectites. These clay phases are characterised by broad bands near $3632 \mathrm{~cm}^{-1}$, between 3500 and $3200 \mathrm{~cm}^{-1}$, and near $1260-1191 \mathrm{~cm}^{-1}$, and a small but sharp peak due to kaolinite at $3698 \mathrm{~cm}^{-1}$ (Fig. $3 a$ ). Dominant negative peaks in the first loading weight spectrum were assigned, according to Fig. 4, to lime (calcium carbonate), with peaks at $2875 \mathrm{~cm}^{-1}, 2590-2516 \mathrm{~cm}^{-1}, 1795 \mathrm{~cm}^{-1}$, and $1494 \mathrm{~cm}^{-1}$.

To confirm the correlation effect of high carbonate concentrations on the loading weight of some of the samples, an additional PLS analysis was performed using only those samples with no detected carbonate (Fig. 3a2). The first loading weight for Fe, depicted in Fig. $3 a 2$ and also typical of the first loading weights for the other trace metals, was now dominated by positive peaks due to clay minerals at $3641-3597 \mathrm{~cm}^{-1}, 1630 \mathrm{~cm}^{-1}$, and at $1194 \mathrm{~cm}^{-1}$, and according to Fig. 4 negative peaks due to quartz (sand) near $2238 \mathrm{~cm}^{-1}$ and 1993-1791 cm $\mathrm{cm}^{-1}$ (Nguyen et al. 1991). Minor negative peaks characteristic of alkyl species for organic matter were observed near $2925-2856 \mathrm{~cm}^{-1}$, and near $3711-3700 \mathrm{~cm}^{-1}$ and $3625 \mathrm{~cm}^{-1}$ for kaolinite. The clay mineral peak at $3597 \mathrm{~cm}^{-1}$ was near $3605 \mathrm{~cm}^{-1}$ for the Fe-rich Mulloorina illite illustrated in Fig. 4. This result suggested that trace metal concentrations were positively correlated with clay minerals, most probably smectite and Fe-rich illite, and inversely correlated with quartz, carbonate when present, and organic matter.

The second loading weights for $\mathrm{Fe}, \mathrm{Mn}, \mathrm{Cu}$, and $\mathrm{Zn}$ are illustrated in Fig. $3 b$. These are characterised by strong positive peaks at $1993-1812 \mathrm{~cm}^{-1}$ due to quartz and weaker peaks near $3700 \mathrm{~cm}^{-1}$ and $3600 \mathrm{~cm}^{-1}$ due to kaolin and illite, respectively. The kaolin peak is particularly strong for $\mathrm{Mn}$ and $\mathrm{Cu}$, and almost absent for $\mathrm{Zn}$, suggesting a slightly different relationship with soil clay. The appearance of positive quartz peaks may be explained by an attempt by the PLS procedure to account for non-linearity in the intensity of the mid-infrared diffuse reflectance spectra due to quartz of varying particle size, but this explanation is purely conjecture. As for the first loading weight, negative organic alkyl peaks can be observed for all metals. 


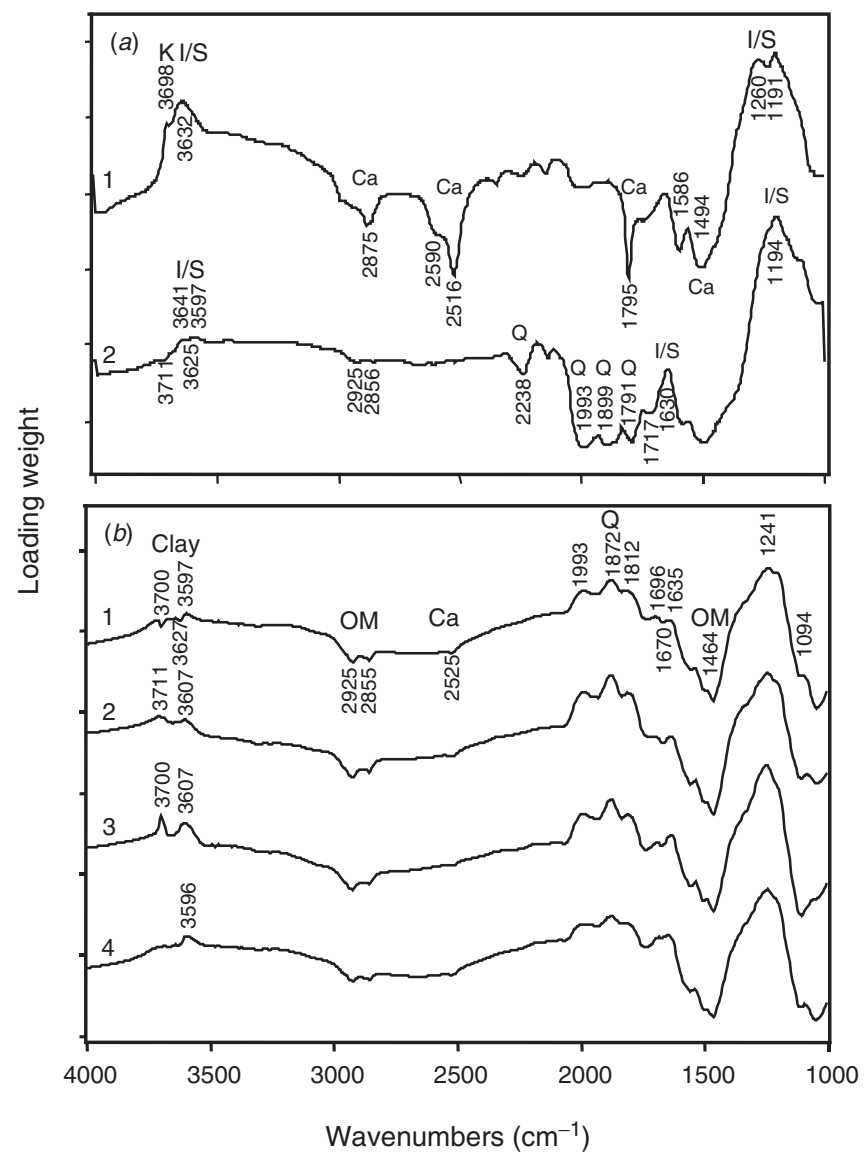

Fig. 3. (a) First weight loadings for iron: $(a 1)$ in all 48 samples and $(a 2)$ in samples without carbonates; and $(b)$ the second weight loading for: $(b 1)$ iron, (b2) manganese, (b3) copper, and (b4) zinc obtained from the PLS analyses of all 48 neat soil samples. Minerals were identified as illite (I), smectite (S), kaolinite (K), calcite $(\mathrm{Ca})$, quartz $(\mathrm{Q})$; organic matter $(\mathrm{OM})$ was also identified.

\section{Effect of $\mathrm{CaCO}_{3}$ concentrations on PLS quantification}

The regression relationships for micronutrients may have been affected by a dilution effect due to the quartz, carbonate, and clay concentrations of the sample. Soils having a low concentration of clay were also those with the lower total micronutrient concentrations (Fig. 5). In addition, samples with the highest amount of sand also contained the lowest amount of clay and, to a lesser extent, carbonate (Fig. 1). Consequently, the dilution effect by sand and/or carbonate could possibly explain the resulting regressions. To test this hypothesis, the MIR-PLS relationships were split on the basis of the carbonate concentrations of the samples. The median value of $2 \% \mathrm{CaCO}_{3}$ was chosen arbitrarily to split the data set into 2 portions, as it allowed for a similar number of samples in the 2 new data subsets (Table 2). For neat samples with $<2 \% \mathrm{CaCO}_{3}$, the regression relationships were significantly better for organic carbon, organic phosphorus and magnesium, and conversely poorer for potassium, sulfur, oxalate extractable $\mathrm{Al}$ and, as expected, $\mathrm{CaCO}_{3}$. Thus, the presence of $\mathrm{CaCO}_{3}$ adversely affected the relationship between spectral data and organic carbon regressions. The large difference obtained for the regression coefficients of organic carbon (Table 2) may be explained by a lack of specificity of organic carbon peaks in the presence of high levels of $\mathrm{CaCO}_{3}$. The poor $R^{2}$ value for sulfur in less calcareous soils, and inspection of the first and second weight loading for $\mathrm{S}$ regression coefficients (data not shown), indicated that $\mathrm{S}$ was mainly correlated with $\mathrm{CaCO}_{3}$. Since the regression for $\mathrm{S}$, 


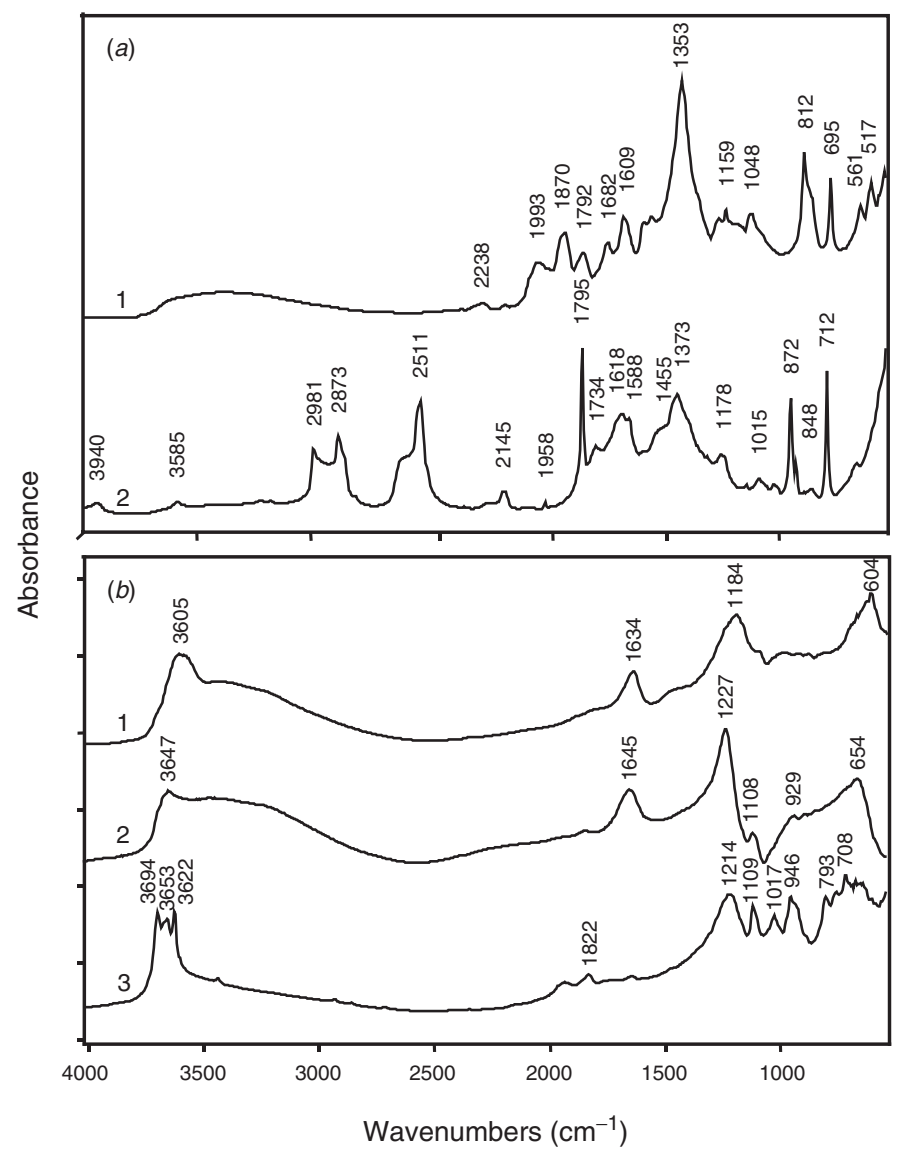

Fig. 4. Infrared spectra of neat standards of $(a 1)$ pure ignited quartz sand, finely ground (a2) pure calcium carbonate (Merck) and (b1) Muloorina illite, (b2) Andamooka-Ca saturated smectite, and (b3) poorly crystalline Georgia kaolinite.

$\mathrm{Al}_{\mathrm{ox}}$, and $\mathrm{P}$ in samples with $>2 \% \mathrm{CaCO}_{3}$ (Table 2) was better than that for calcium carbonate-poor soils (Table 2), this confirmed the important role of $\mathrm{CaCO}_{3}$ concentration on these regressions. For $\mathrm{P}$, higher regression coefficients could be obtained using a more appropriate calibration set. Effectively, at high concentrations of $\mathrm{P}$ and in presence of calcium carbonate such as in calcareous soil, the formation of Ca-P compounds is likely (Freeman and Rowell 1981). These precipitations may cause the MIR spectra to become atypical of the remaining calibration set leading to difficulties in predictions. The regression coefficients for metals such as $\mathrm{Cu}, \mathrm{Zn}, \mathrm{Al}$, and Fe were statistically independent of the $\mathrm{CaCO}_{3}$ concentration. For $\mathrm{Mn}$, the $R^{2}$ was only 0.58 for samples with $>2 \% \mathrm{CaCO}_{3}$ compared with 0.88 for samples with $<2 \% \mathrm{CaCO}_{3}$. Consequently, the high $\mathrm{Mn}$ correlation may have resulted from a dilution effect of carbonate on quartz, i.e. when the $\mathrm{CaCO}_{3}$ concentration increases, the quartz and clay concentrations decrease. Another possible explanation was that Mn could be occluded in calcium carbonates particles and just not seen by MIR in calcareous soils. However, these explanations are inconclusive, as the differences between regression coefficients for $\mathrm{Mn}$ were not statistically significant 

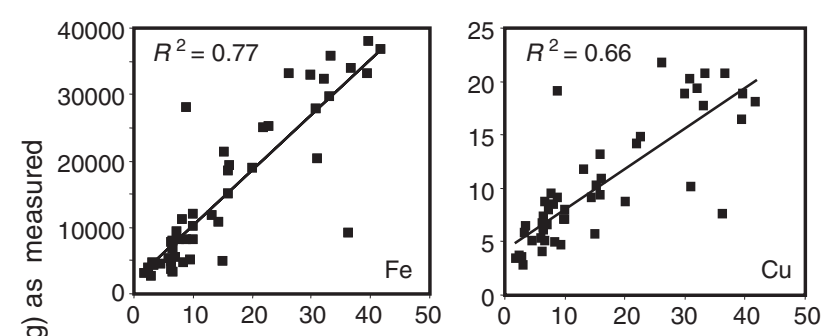

Fig. 5. Regression between clay concentration and total concentration (as measured in laboratory) for iron (Fe), copper

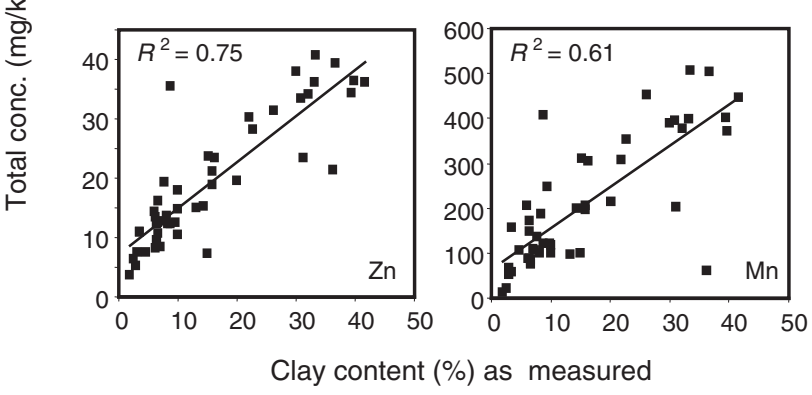
$(\mathrm{Cu})$, zinc $(\mathrm{Zn})$, and manganese (Mn). The whole soil set was considered, i.e. 48 soils.

(Table 2). Even if the regression coefficients for $\mathrm{Zn}, \mathrm{Cu}, \mathrm{Al}$, and $\mathrm{Fe}$ were not influenced by the carbonate, dilution by quartz remains one possible explanation for the good regressions obtained. In addition, trace metal concentration was mainly related to the clay concentration of the soils (Fig. 3). However, as the correlation between laboratory-determined clay concentration and laboratory-determined metal concentrations for the 48 soils (Fig. 5) was lower than the regression coefficients determined between MIR-PLS derived metal concentrations and laboratory-determined metal concentrations (Fig. 2), we can thus conclude that clay concentration was not the only property which influenced the relationship. It appears from Figs 3 and 5 that the type of clay, e.g. smectite, illite, or kaolinite, also plays an important role in the determination of metal concentrations in alkaline soils.

\section{Assessing solid phase associations of nutrient and micronutrient}

Table 3 represent the regression coefficients obtained from the regression of $(i)$ measured laboratory concentrations of the clay fraction correlated with the MIR-derived concentrations from the spectra of the clay fraction, (ii) laboratory analyses of the whole soil with the analyses derived from MIR of the clay fraction, (iii) measured laboratory analyses of the whole soil with the analyses derived from the MIR spectra of the clay fraction without carbonates and after a CBD extraction, respectively. The observation of the clay fraction spectra (data not shown) indicates that only 23 clay samples were totally free of $\mathrm{CaCO}_{3}$ after extraction.

A large part of the chemical elements was removed during extraction of the clay fraction (Table 3). In most cases $>30 \%$ of the trace elements were lost probably by an exchange process with the concentrated $\mathrm{NaCl}$ and $\mathrm{CaCl}_{2}$ solutions used during extraction. In addition, successive extractions were performed leading to desorption of exchangeable ions. This may also explain the high losses of chemical elements observed. The regressions obtained from MIR-PLS analysis performed between clay fractions and chemical analysis of the clay fraction were high for all the elements that are typical of the clay structure such as Fe, Al, and to a lesser extent $\mathrm{K}$ and $\mathrm{Mg}$ (Table 3). In the case of $\mathrm{Zn}, \mathrm{Cu}$, and $\mathrm{Mn}$, the regression 
coefficients were poorer when the MIR-PLS analyses were performed between the clay spectra and laboratory clay analyses rather than the clay spectra and the laboratory whole soil analyses (Table 3). However, considering the fact that even when the regressions were performed between the clay spectra and the laboratory whole soil analyses, the $R^{2}$ values were always $>0.50$, it was thus concluded, as expected, that the clay fractions played a major role in the retention of $\mathrm{Zn}, \mathrm{Cu}, \mathrm{Al}$, and $\mathrm{Fe}$ in these soils.

For calcareous samples, regression relationships for $\mathrm{S}, \mathrm{Al}_{\mathrm{ox}}, \mathrm{Fe}_{\mathrm{ox}}, \mathrm{Mn}_{\mathrm{ox}}, \mathrm{Si}_{\mathrm{ox}}$, and $\mathrm{Fe}_{\mathrm{ox}}$ (Table 3) with infrared spectral characteristics of the clay fraction were $10-53 \%$ better than the regressions for the clay spectra without carbonate and laboratory determined whole soil analyses (Table 3). These data confirmed the role of $\mathrm{CaCO}_{3}$ in the retention of these elements in soil. For sulfur (S), for example, the regression coefficient $\left(R^{2}\right)$ was $53 \%$ better in the samples containing $\mathrm{CaCO}_{3}$, thus confirming the association of $\mathrm{S}$ with $\mathrm{CaCO}_{3}$ as previously suggested. The most likely form of $\mathrm{S}$ in these soils is gypsum, co-precipitated with the $\mathrm{CaCO}_{3}$. Conversely, the regression for $\mathrm{Mg}$ was $53 \%$ better when performed from the clay fraction spectra without carbonate (Table 3), thus confirming the same tendency already observed in Table 2. The large difference between regressions performed between clay spectra and whole soil analysis and CDB-clay spectra (Table 3) with laboratory-determined whole soil analysis strongly suggests that a substantial proportion of $\mathrm{Mg}$ was associated with iron or aluminium oxides possibly as well as within clay minerals. All the regressions performed with oxalate-extractable elements improved by $20-30 \%$ in soils containing $\mathrm{CaCO}_{3}$ compared with soils without (Table 3).

The presence of carbonate did not affect regressions from the MIR-PLS analyses performed between the clay spectra and the laboratory whole soil analysis for $\mathrm{Mn}, \mathrm{Cu}$, and $\mathrm{Zn}$ (Table 3). The weight loadings of these micronutrients (Fig. 6) confirm that they were mainly associated with clay minerals. The first weight loading for Fe, depicted in Fig. 6, was similar to that of $\mathrm{Mn}, \mathrm{Cu}$, and $\mathrm{Zn}$ (not shown) and showed positive peaks due to an

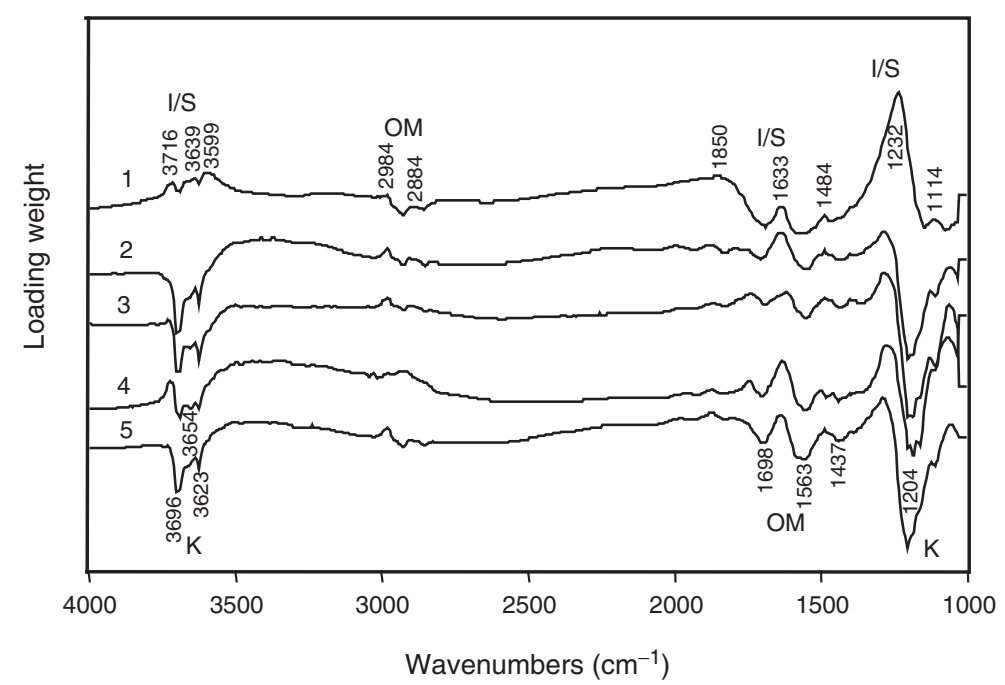

Fig. 6. First weight loadings for (1) iron and second weight loading for (2) iron, (3) copper, (4) zinc, and (5) manganese obtained from the PLS analyses of the clay fraction without carbonates and soil data. Minerals were identified as illite (I), smectite (S), kaolinite $(\mathrm{K})$, calcite $(\mathrm{C})$, quartz $(\mathrm{Q})$, and iron oxide $(\mathrm{Fe}-\mathrm{O})$. 
Fe-rich 2:1 layer alumino-silicate clay mineral indicated by peaks near $3600 \mathrm{~cm}^{-1}, 1633$ $\mathrm{cm}^{-1}$, and near $1232 \mathrm{~cm}^{-1}$. In the second loading weight, negative peaks, suggesting a negative correlation with metal, were observed at 3696 and $3623 \mathrm{~cm}^{-1}$ for kaolinite and 2930 and $2860 \mathrm{~cm}^{-1}$ for organic matter. Sharp, strong negative peaks were observed in the second loading weight for all metals at 3696 and $3623 \mathrm{~cm}^{-1}$ due to kaolinite, near 1698 and $1563 \mathrm{~cm}^{-1}$ due to organic matter, and near $1204 \mathrm{~cm}^{-1}$ due to kaolinite. Additional positive peaks at 2984 and $2884 \mathrm{~cm}^{-1}$ suggested some contamination by acetate used in the preparation of the clay fractions.

XRD (data not shown) of the clay fractions showed that samples with high concentrations of metals, such as $\mathrm{Mn}, \mathrm{Cu}$, and $\mathrm{Zn}$, had a low concentration of kaolinite and a higher concentration of smectite. This is consistent with the infrared results, which suggested a positive relationship with smectite/illite and negative relationship with kaolinite. Traces of hematite were identified by XRD, but not in sufficient amounts to be quantified. Essentially, the XRD results confirmed the spectra observed in Fig. 6.

In this study, there appeared to be no association between micronutrients, and $\mathrm{Cu}$ and organic matter. Previous studies have reported that organic matter, and its differing constituents (humic and fulvic acids), have been found to strongly bind $\mathrm{Cu}$, and consequently influence $\mathrm{Cu}$ availability for plants (Petruzzelli and Buidi 1976; Peverill et al. 1999). However, most of the work previously performed on the dynamics of copper in soils was focussed on the available, or exchangeable, pool of $\mathrm{Cu}$. This pool represents only a very small fraction of the total copper in soils. As IR peaks corresponding to organic matter were very small, they were considered to have an insignificant influence on the PLS analyses for the regressions for $\mathrm{Cu}$. It was therefore concluded that the clay concentration, and particularly the type of clay, has more influence on the distribution of $\mathrm{Cu}$ concentrations in these alkaline soils than organic matter.

The regressions obtained from the laboratory-determined whole soil analysis and MIR spectra of the clay fraction after CDB extraction (Table 3) were considerably poorer for $\mathrm{Cu}$, $\mathrm{Zn}$, and particularly $\mathrm{Mn}$ after removal of the iron and aluminium oxides. Even if these elements were mainly associated with the clay mineral as interlayer cations (smectites) or with the clay mineral lattice, iron and/or aluminium oxides in the clay fraction also play an important role in the retention of micronutrients and especially Mn. The CBD extraction does not completely remove all the Fe and $\mathrm{Al}$ present (analyses not shown); a portion of these elements appears to be incorporated within the clay structure. Consequently, in the clay fraction, the relationships between the major structural elements such as $\mathrm{Fe}, \mathrm{Al}$, and $\mathrm{Si}$ remained; however, the regression coefficients were poorer as expected.

\section{Use of a partitioning model to predict metal availability}

The regression relationships determined by MIR-PLS allows the rapid analysis of soils to determine total concentrations of several micronutrients. In terms of soil fertility, total concentrations are not sufficient in themselves, but combined with models of metal availability (Sauvé et al. 2000), the technique offers the possibility of rapidly determining concentrations of available micronutrients or contaminants in soil solution. The model proposed by Sauvé et al. (2000) uses the total concentration of elements in soils, pH, and soil organic matter in the Eqns 1 and 2 for $\mathrm{Zn}$ and $\mathrm{Cu}$, respectively:

$$
\begin{gathered}
\log _{10}\left(\mathrm{Zn}_{\mathrm{s}}\right)=-0.55 \pm 0.04 * \mathrm{pH}+0.94 \pm 0.08 * \log _{10}(\text { total } \mathrm{Zn})-0.34 \pm 0.12 \\
* \log _{10}(\mathrm{SOM})+3.68 \pm 0.31
\end{gathered}
$$



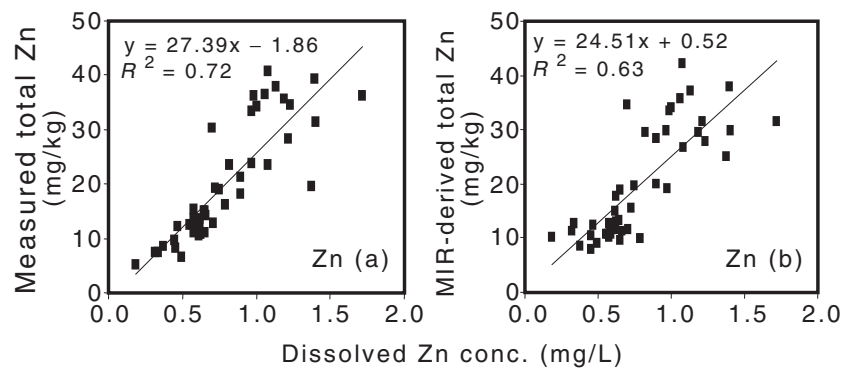

Fig. 7. Linear regressions of dissolved metal $(\mathrm{Zn}$ and $\mathrm{Cu})$ concentrations $(\mathrm{mg} / \mathrm{L})$ deduced from the model of Sauve et al.
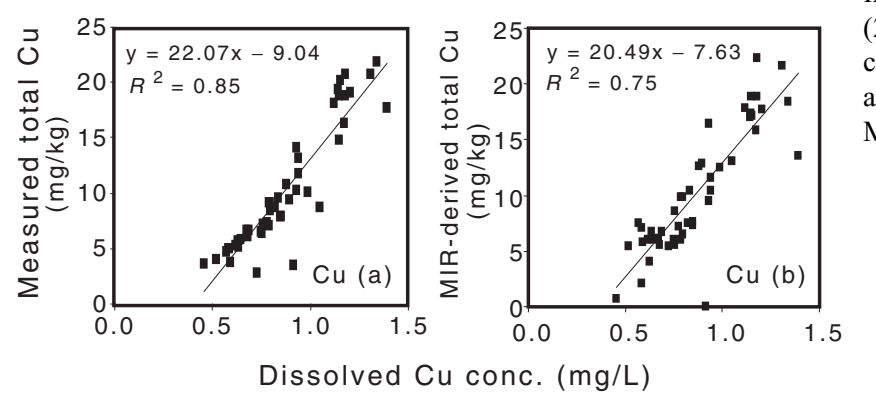
(2000) as a function of total concentration $(a)$ as measured, and $(b)$ as derived from MIR-PLS analyses.

$$
\begin{gathered}
\log _{10}\left(\mathrm{Cu}_{\mathrm{s}}\right)=-0.21 \pm 0.02 * \mathrm{pH}+0.93 \pm 0.05 * \log _{10}(\text { total } \mathrm{Cu})-0.21 \pm 0.02 \\
* \log _{10}(\mathrm{SOM})+1.37 \pm 0.14
\end{gathered}
$$

with soil organic matter (SOM) expressed as $\% \mathrm{C}$, and total element concentration (total) expressed as mg/kg of dry soil (from Sauvé et al. 2000). $\mathrm{Zn}_{\mathrm{s}}$ and $\mathrm{Cu}_{\mathrm{s}}$ are the concentrations of $\mathrm{Zn}$ and $\mathrm{Cu}$ in solution as $\mathrm{mg} / \mathrm{L}$, respectively.

Figure 7 shows the relationships of MIR-derived total concentrations of $\mathrm{Cu}$ and $\mathrm{Zn}$ versus dissolved $\mathrm{Cu}$ and $\mathrm{Zn}$ as deduced from the Eqns 1 and 2 . The same relationships with laboratory-measured concentrations are also reported. In both cases, the regression coefficients $\left(R^{2}\right)$ were reduced by using the MIR-derived total concentration values instead of the measured concentration. However, even with the reduced $R^{2}$, the relationships between MIR derived total concentration and dissolved concentration in soils remains good (Fig. 7) and constitutes a convenient and practical rapid means of evaluating the mobile pools of metals or nutrients.

\section{Conclusions}

This study demonstrated that MIR-PLS analysis is a powerful and rapid technique to assess the grouping of soil samples on the basis of their common mineralogy. In addition, in alkaline soils from southern Australia, with the exception of mineral and organic $\mathrm{P}$ and $\mathrm{C}$, the regression relationships of the macro- and micronutrient concentrations could be correctly predicted by this technique. The loading weight indicated that micronutrients were associated with the clay fraction and dependent on the type of clay present. A positive correlation was found between micronutrients, such as $\mathrm{Cu}, \mathrm{Zn}, \mathrm{Mn}, \mathrm{Fe}$, and smectite/illite, and conversely, a negative relation with kaolinite. Manganese was exclusively related to the content of iron and aluminium oxides, whereas $\mathrm{Cu}$ and $\mathrm{Zn}$ were related to these to a lesser extent. Inspection of the PLS weight loadings enabled us to conclude that, in calcareous soils, sulfur (S) was associated with carbonate and conversely that $\mathrm{Mg}$ was more related to the clay concentration of soils. Taking into account that soil sample preparation with 
MIR-PLS analysis takes only about 2 min for scanning and predictions of ground samples, and that more than 15 chemical properties can be predicted using this technique, MIR-PLS analysis provides a rapid and inexpensive technique for the assessment of several key soil characteristics. In addition, by using MIR-PLS and a partitioning model such as the one described by Sauvé et al. (2000) for metals, the potential bioavailability of several metal micronutrients could be rapidly determined. For the present study, the relatively small numbers of samples used to model the PLS analyses was clearly sufficient as a research or pilot study on Australian alkaline soils. However, many more samples, including a larger variety of soil types, would obviously have to be included for use as an established analytical technique.

\section{Acknowledgments}

The authors thank the Grains Research and Development Corporation (Project No. CSO200) for providing funding support for this research program. We wish also to thank Dr J. Churchman, Mr R. Merry, Dr W. Gates, and Dr R. Correll for valuable discussion and helpful comments on the manuscript.

\section{References}

Barbanti A, Bergamini MC, Frascari F, Miserocchi S, Rosso G (1994) Critical aspects of sedimentary phosphorus chemical fractionation. Journal of Environmental Quality 23, 1093-1102.

Ben-Dor E, Banin A (1990) Near-infrared reflectance analysis of carbonate concentration in soils. Applied Spectroscopy 44, 1064-1069.

Chang SC, Jackson ML (1957) Fractionation of soil phosphorus. Soil Science 59, 133-144.

Flores-Vélez LM, Ducaroir J, Jaunet AM, Robert M (1996) Study of the distribution of copper in an acid sandy vineyard soil by three different methods. European Journal of Soil Science 47, 523-532.

Ford GW, Martin JJ, Rengasamy P, Boucher SC, Ellington A (1993) Soil sodicity in Victoria. Australian Journal of Soil Research 31, 869-909.

Freeman JS, Rowell DL (1981) The adsorption and precipitation of phosphate onto calcite. Journal of Soil Science 32, 75-84.

Haaland DM, Thomas VT (1988) Partial least-square methods for spectral analyses. I. Relation to other quantitative calibration methods and the extraction of qualitative information. Analytical Chemistry 60 , $1193-1202$.

Heanes DL (1984) Determination of total organic-C in soils by an improved chromic acid digestion and spectrophotometric procedure. Communications in Soil Science and Plant Analysis 15, 1191-1213.

Holloway RE, Bertrand I, Frischke A, Brace DM, McLaughlin MJ, Sheppard W (2001) Improving fertiliser efficiency on highly calcareous and alkaline soils with fluid sources of P, N and Zn. Plant and Soil 236, 209-219

Holmgen A, Norden B (1988) Characterization of peat samples by diffuse reflectance Ft-IR spectroscopy. Applied Spectroscopy 42, 225-262.

Isbell RF (1996) 'The Australian soil classification.' (CSIRO Publishing: Melbourne)

Jackson ML (1956) Soil chemical analysis. Advanced course. Department of Soils, University of Wisconsin, Madison, p. 991.

Janik LJ, Merry RH, Skjemstad JO (1998) Can mid infrared diffuse reflectance analysis replace soil extractions? Australian Journal of Experimental Agriculture 38, 681-696.

Janik LJ, Skjemstad JO (1995) Characterization and analysis of soils using mid-infrared partial least-squares. II. Correlations with some laboratory data. Australian Journal of Soil Science 33, 637-650.

Janik LJ, Skjemstad JO, Raven MD (1995) Characterization and analysis of soils from eastern Australia using mid-infrared partial least-squares. I. Correlations with XRF determined major element chemistry. Australian Journal of Soil Science 33, 621-636.

Krischenko VP, Samokhvalov SG, Fomina LG, Novikova GA (1992) Use of infrared spectroscopy for the determination of some properties of soil. In 'Advances in near infrared spectrsocopy'. (Eds I Murray, IA Cowe) pp. 239-249. (WCH, Weinheim: New York) 
Malley F, Yesmin L, Wray D, Edwards S (1999) Application of near-infrared spectroscopy in analysis of soil mineral nutrients. Communications in Soil Science and Plant Analysis 30, 999-1012.

Martin AE, Reeve R (1955) A rapid manometric method for determining soil carbonate. Soil Science 79, $187-197$.

Matar AE, Torrent J, Ryan J (1992) Soil and fertilizer phosphorus and crop responses in the dryland Mediterranean zone. Advances in Soil Science 18, 81-146.

McKeague JA, Day JH (1966) Dithionite and oxalate extractable Fe and Al as aids in differentiating various classes of soils. Canadian Journal of Soil Science 46, 13-22.

McKenzie N, Isbell RE, Brown K, Jacquier D (1999) Major soils used for agriculture in Australia. In 'Soil analysis an interpretation manual'. (Eds KI Peverill, LA Sparrow, DJ Reuter) Chapter V, pp. 71-102. (CSIRO Publishing: Melbourne)

Nguyen TT, Janik LJ, Raupach M (1991) Diffuse Reflectance Infrared Fourier Transform (DRIFT) spectroscopy in soil studies. Australian Journal of Soil Research 29, 49-67.

Peverill KI, Sparrow LA, Reuter DJ (1989) 'Soil analysis: An interpretation manual.' (CSIRO publishing: Melbourne)

Piccolo A, Stevenson FJ (1992) Infrared spectra of $\mathrm{Cu}^{2+}, \mathrm{Pb}^{2+}, \mathrm{Ca}^{2+}$, complexes of soil humic substances. Geoderma 27, 95-208.

Petruzzelli G, Buidi G (1976) Influence of soil organic matter on copper availability to plants. Zeitschrift fur Pflanzenernahrung und Bodenkunde 6, 679.

Rayment GE, Higginson FR (1992) 'Australian laboratory handbook of soil and water chemical methods.' 330 pp. (Inkata Press: Melbourne)

Saggar S, Hedley MJ, White RE, Perrott KW, Gregg PEH, Cornforth IS, Sinclair AG (1999) Development and evaluation of an improve soil test for phosphorus, 3: field comparison of Olsen, Colwell and Resin soil P test for New Zealand pasture soils. Nutrient Cycling in Agroecosystems 55, 35-50.

Sauvé S, Hendershot W, Allen HE (2000) Solid-solution partitioning of metals in contaminated soils: Dependence on $\mathrm{pH}$, total metal burden, and organic matter. Environmental Science and Technology 34,1125-1131.

Schnitzer M (1965) The application of infrared spectroscopy to investigations on soil humic components. Canadian Journal of Spectroscopy 10, 121-127.

Schwertmann U (1964) Differenzierung der Eisenoxide des Boden durch Extraktion mit Ammoniumoxalat-Lösung. Zeitschrift fur Pflanzenernahrung und Bodenkunde 105, 194-202.

Simpson PG, Weatherley AJ, Sale PWG, McLaughlin MJ, Hoy V, Lancaster P (1997) Assessment of soil phosphorus tests for situations in Australia where reactive phosphate rock and water-soluble phosphorus fertilisers are used. Australian Journal of Experimental Agriculture 37, 1027-1035.

Stenberg BO, Nordkvist E, Salomonsson L (1995) Use of near infrared reflectance spectra of soils for objective selection of samples. Soil Science 159, 109-114.

USEPA (1993) 'Standard for the use and disposal of sewage sludge.' Method SW 3051A, 3rd edn (United States Environment Protection Agency)

Walker TW, Adams AFR (1958) Studies on soil organic matter: I. Influence of phosphorus concentration of parent materials on accumulation of carbon, nitrogen, sulfur and organic phosphorus in grassland soils. Soil Science $\mathbf{8 5}, 307-318$

Manuscript received 21 November 2001, accepted 24 June 2002 